\title{
KAJIAN KERUSAKAN MATERIAL SUPERHEATER TUBE 2" DENGAN PENDEKATAN STANDAR ASTM
}

\author{
Koos Sardjono Kuntadi P
}

\begin{abstract}
Equipments used in industry process and migas is generally designed from alloy of steel which hold up to high temperature and attack corrosion. Based on that, it's require to be conducted an material operation and election, like a component Boiler that is Secondary Superheater is generally weared by pipe from alloy of steel material Cr-Mo or steel with Austenitik type.

To know the damage of Secondary Superheater tube 2" material, can be conducted by a chemical composition analysis, test inspection metalografi and hardness.

The damage of Material Secondary Superheater tube 2" at the extension las elbow in the form of rip on second potition (ASTM SA - 192) representing a militant low strength carbon material pipe, while on the first potition which there are not pipe material damage representing a militant high strength carbon (ASTM SA - 106 grade C) which a different thick each other. Attenuating showed the thick degradation which possible because of local stream turbulensi warm-up existence and which is high enough, this matter is shown with existence transformasi perlit become to the karbida particles which speroidisasi crust existence and rip area on the surface of the pipe.
\end{abstract}

Keywords: pipe, extension las, material damage, perlit and ferrite, karbida particle, speroidisasi, stream turbulensi, local hot.

\section{PENDAHULUAN}

Pipa diameter 2", dipergunakan untuk komponen ketel uap (boiler) yaitu pada Secondary Superheater (pemanas lanjut kedua) yang telah mengalami kerusakan berbentuk pecahan (sobekan) disekitar sambungan las. Posisi pipa yang sobek ada dibawah sambungan las, sedangkan aliran uap bergerak dari bawah keatas. Pipa tersebut dibawa ke Laboratorium Analisa Kerusakan dan Umur Sisa (AKUS) untuk dilakukan investigasi penyebab kerusakannya dan dicarikan solusinya agar tidak terulang kembali.

\section{DASAR TEORI}

Menurut R. Viswanathan, komponen Superheater harus memiliki sifat utama seperti: Kemampuan las yang baik, kekuatan terhadap Creep, ketahanan terhadap oksidasi dan koefisien muai termal yang rendah. Untuk memenuhi sifat-sifat utama tersebut, maka tipetipe material yang dapat memenuhi persyaratan diatas adalah baja paduan $\mathrm{Cr}-\mathrm{Mo}$ dan baja tahan karat Austenitik. Sedangkan mekanisme kerusakan yang terjadi pada ketel uap adalah sebagai berikut: Stress-Rupture, Water-side corrosion, Fire-side corrosion, Erosion, Fatigue dan Lack of Quality Control. Kerusakan pada sambungan las dari dua logam yang berbeda jenis termasuk dalam Stress-Rupture, hal ini sering terjadi karena kemungkinan didalam perbaikan dan pe-rawatan mencari pipa yang tipe materialnya sama kadang-kadang tidak mudah sehingga dilapangan diputuskan penggunaan material yang berbeda tipenya seperti pipa baja Ferritik dan pipa baja Austenitik dan lain sebagainya, karena adanya perbedaan koefisien muai termal ekspansi sehingga akan mengakibatkan kerusakan pada sisi pipa baja Ferritik didaerah pengaruh panas las (Heat Affected Zone = HAZ).

\section{METODE PENELITIAN}

Untuk mengetahui penyebab dan metode yang efektif untuk menghindari terjadinya kerusakan pipa Secondary Superheater, maka dilakukan pengkajian / analisa kerusakan terhadap material pipa dengan terlebih dahulu mengetahui datadata teknis nya sebagai berikut:

Temperature Operasi $: 400-500^{\circ} \mathrm{C}$

Tekanan Operasi $\quad: 80 \mathrm{~kg} / \mathrm{cm}^{2}$

Fluida kerja : Uap

Arah aliran : Vertikal dari bawah

keatas

Kemudian dilakukan pengujian terhadap material pipa 2" dari Secondary Superheater dengan beberapa metode pemeriksaan atau penelitian, yaitu:

a. Analisa Komposisi Kimia (Chemical Composition Analysis)

b. Uji Kekerasan (Hardness Test),

c. Pemeriksaan Metalografi ( Metallography examination ) 


\section{HASIL DAN PEMBAHASAN}

\subsection{Hasil}

\subsubsection{Analisa Komposisi Kimia (Chemical Composition Analysis)}

Hasil analisa komposisi kimia pipa 2" dari Secondary Superheater (lampiran 1) menunjukkan bahwa kandungan unsur material sesuai dengan standar yang diacu yaitu ASTM SA- 92 dan SA - 106 grade C terlihat pada Tabel 1.

\subsubsection{Uji Kekerasan (Hardness Test)}

Hasil uji kekerasan dengan metode Vickers terhadap sampel material baja karbon dari secondary superheater tube diameter 2" (lampiran 2) menunjukkan bahwa nilai kekerasan material dasar ( Base Material = BM ) rata - rata diposisi 1 (sampel 3,4 dan 5) adalah $161.8 \mathrm{HV}$, dan rata-rata diposisi 2 (sampel 1 dan 2) adalah 101.1 HV, sedangkan nilai kekerasan material menurut acuan standar ASTM SA-192 yaitu minimal $100 \mathrm{HV}$, sehingga ditinjau dari sifat kekerasan bahan atau materialnya lebih mendekati ke baja karbon kekuatan tinggi dalam standar ASTM SA -106 grade C dengan kekerasan minimal $160 \mathrm{HV}$. Jadi pipa dengan sambungan las mempunyai dua macam karak- teristik, yaitu yang berada pada posisi 1 identik dengan ASTM SA-106 grade C sedangkan yang berada pada posisi 2 identik dengan ASTM SA-192.

\subsubsection{Pemeriksaan Metalografi (Metallography Examination)}

Hasil pemeriksaan metalografi (lihat gambar 2 s/d 14) menunjukkan bahwa struktur mikro material baja karbon untuk komponen Boiler yaitu Secondary Superheater berupa matriks struktur feritik dengan partikel karbida speroidisasi perlit terutama pada sampel di posisi 2 . Kemudian ditemukan adanya deposit atau kerak (Scale) pada sisi diameter luar. Dari hasil pemeriksaan metalografi menunjukkan bah-wa terjadi overheating disisi permukaan pipa luar yang terjadi kerusakan berupa sobekan, sedang adanya perbedaan ketebalan pipa dimana pada posisi 1 ( $\left.\mathrm{t}_{1}\right) 5 \mathrm{~mm}$ sedang pada posisi $2\left(\mathrm{t}_{2}\right) 3.5$ $\mathrm{mm}$, kemungkinan dapat meng-akibatkan proses aliran turbulensi dari uap, sehingga dapat mengakibatkan erosi pada permukaan sisi dalam diameter pipa dimana terukur pada sampel 1 dengan ketebalan hanya $1.25 \mathrm{~mm}$.

Tabel 1 Perbandingan Hasil Uji Komposisi Kimia Pipa 2" dari Secondary Superheater dengan Standar ASTM SA - 192 dan SA - 106 gr C

\begin{tabular}{|c|c|c|c|c|c|}
\hline \multirow{2}{*}{ No. } & \multirow{2}{*}{ Elemen } & \multicolumn{2}{|c|}{ Hasil Uji (\% Berat ) } & \multicolumn{2}{c|}{ ASTM } \\
\cline { 3 - 6 } & & Posisi 1 & Posisi 2 & SA - 192 & SA-106 gr.C \\
\hline 1. & $\mathrm{C}$ & 0.15 & 0.13 & $0.06-0.18-$ & 0.35 \\
\hline 2. & $\mathrm{Si}$ & 0.20 & 0.23 & 0,25 & $0.1 \mathrm{~min}$. \\
\hline 3. & $\mathrm{Mn}$ & 0.73 & 0.47 & $0.27-0.63$ & $0.29-1.06$ \\
\hline 4. & $\mathrm{Cr}$ & 0.14 & 0.0 & --- & --- \\
\hline 5. & $\mathrm{Ni}$ & 0.041 & 0.0 & --- & --- \\
\hline 6. & $\mathrm{Mo}$ & 0.0 & 0.0 & --- & --- \\
\hline 7. & $\mathrm{~S}$ & 0.011 & 0.016 & 0.058 & 0.058 \\
\hline 8. & $\mathrm{P}$ & 0.015 & 0.028 & 0.048 & 0.048 \\
\hline
\end{tabular}

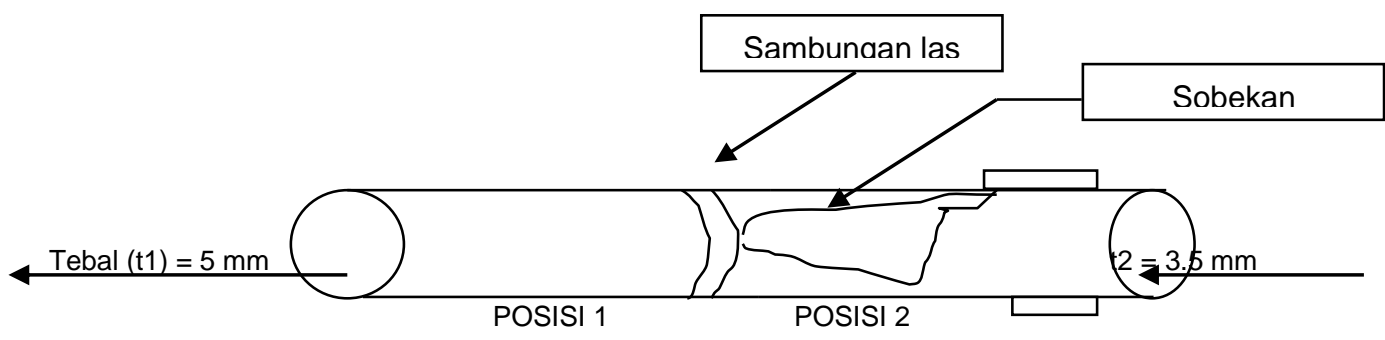

Gambar 1 Skema Posisi Pipa Secondary Superheater 


\subsubsection{Pembahasan}

Dari hasil analisa komposisi kimia menunjukkan bahwa pipa pada posisi 1 dan posisi 2 berbeda jenisnya, yaitu yang berada pada posisi 1 identik dengan ASTM SA -106 grade C ialah baja karbon dengan kekuatan tinggi sedangkan yang berada pada posisi 2 identik dengan ASTM SA 192 ialah baja karbon dengan kekuatan rendah (ref.1).

Pemeriksaan visual dan makro metalografi menunjukkan bahwa material baja karbon pada pipa 2" Secondary Superheater mengalami kerusakan berupa sobekan pada posisi 2 (lihat gambar 2,3 dan 4) yang diperkirakan akibat adanya tegangan yang bekerja pada area tersebut karena terjadi penipisan hingga 1.25 $\mathrm{mm}$ dari tebal semula $\mathrm{t}_{2}=3.5 \mathrm{~mm}$ (lihat gambar 6 ). Kemudian dari pengukuran diameter pipa dan ketebalan (lihat gambar 5) ada perbedaan ketebalan yaitu ketebalan pipa (Wall Thickness=WT) dimana pada posisi $1\left(\mathrm{t}_{1}\right) 5 \mathrm{~mm}$ sedang pada posisi 2 ( $\left.\mathrm{t}_{2}\right) 3.5 \mathrm{~mm}$, hal ini kemungkinan dapat mengakibatkan proses aliran turbulensi dari uap, sehingga dapat mengakibatkan erosi pada permukaan sisi dalam diameter pipa dimana terukur pada sampel 1 dengan ketebalan hanya $1.25 \mathrm{~mm}$ dan dapat membantu terjadinya kerusakan berupa sobekan. Adanya perbedaan ukuran diameter dalam (Inlet Diameter=ID) dan diameter luar (Outlet Diameter=OD) dapat merupakan indikasi terjadinya overheating, hal ini terutama disebab-kan oleh penebalan karena deposit atau kerak pada sisi diameter luar dari sampel 3 di perbatasan sambungan las dan posisi 1 (Gambar 11).

Dari hasil pemeriksaan mikro metalografi (lihat Gambar 9 s/d 14) diketahui bahwa karakteristik kerusakan berupa Thin - Lip Rupture karena terjadinya Rapid Overheating (ref.2) atau direferensi 1 disebut Stress Rupture karena High - Temperature Creep, hal ini ditandai dengan adanya degradasi material dan deformasi permanen, serta hadirnya tegangan pada kondisi aktualnya, yang mana analisa mikro metalografinya berupa matriks feritik dengan banyak partikel karbida disisi permukaan atas pipa yang sobek dan merupakan dekomposisi perlit menjadi partikel - partikel karbida speroidal (ref.3).

Penyebab terjadinya Rapid Overheating, High - Temperature Creep atau disebut juga Long - Term Overheating Failure diperkirakan oleh adanya pengoperasian yang tidak sesuai, seperti pengiriman panas pada suhu tinggi kedalam sistem dengan sangat cepat, sehingga kemampuan dari Secondary Superheater untuk mentransmisikan panas ke fluida kerjanya belum 76 lagi tercapai tetapi panas pembakaran sudah berada pada suhu yang tinggi.

\section{KESIMPULAN}

Dari hasil pemeriksaan dan pembahasan dapat ditarik kesimpulan sebagai berikut:

a. Material Secondary Superheater mempunyai dua karakteristik dan ketebalan yang berbeda yaitu, pada posisi 1 di sisi atas berupa baja karbon kekuatan tinggi (ASTM SA-106 grade C) tebal $5 \mathrm{~mm}$ dan pada posisi 2 di sisi bawah baja karbon kekuatan rendah (ASTM SA - 192) tebal 3,5 mm.

b. Kerusakan material pipa 2" Secondary Superheater berupa sobekan dikarenakan Rapid Overheating atau Long - Term Overheating, terlihat melalui mikro metalo-grafi adanya partikel - partikel karbida dari struktur perlit yang tersperoidisasi.

c. Penyebab yang mendukung yaitu; adanya sambungan las sehingga timbul tegangan (Stress) pada pipa, ketebalan pipa (WT) yang berbeda, sehingga kemungkinan timbul erosi dan aliran yang tidak stabil (Turbulence Flow) menyebabkan penipisan pada diameter dalam (Inlet Diameter=ID) sedangkan pada sisi yang lain ada penebalan kemungkinan disebabkan deposit/kerak (Scale) akibat pengoperasian Superheater yang tidak sesuai dengan prosedur.

\section{SARAN}

6.1 Kurangi atau hilangkan tegangan (Stress) yang bekerja pada pipa.

6.2 Jangan memakai pipa yang ada sambungan las.

6.3 Jangan memakai pipa yang karakteristik dan dimensinya berbeda.

6.4 Mengoperasikan Boiler hendaklah sesuai dengan standar prosedur operasionalnya.

\section{DAFTAR PUSTAKA}

1. Viswanathan R., Damage Mechanisms And Life Assessment of High - Temperature Component, ASM International, Ohio 1989.

2. Hand Book of ASM Standards, Vol. 11, "Failure Analysis and Prevention", American Society for Materials, Philadelphia 1998 
3. Metallurgical Failures In Fossil Fired Boilers, Second Edition, John Wiley \& Sons, New York 1983.

\section{BIODATA}

Koos Sadjono Kuntadi P, dilahirkan di Semarang pada tanggal 8 Mei 1949. Penulis, menyelesaikan program S2 di Fakultas Pasca Sarjana UI bidang MIPA dengan program Materials Science, pada tahun 1991. Saat ini Penulis bekerja pada B2TKS/BPPT di PUSPIPTEK Serpong, sebagai staf peneliti bidang Kajian Material. 


\section{LAMPIRAN 1}

\begin{tabular}{|c|c|c|c|}
\hline Pemakai Jasa & Bahan & & \\
\hline $\begin{array}{l}\text { Customer } \\
\text { Tanggal }\end{array}$ & - & $\begin{array}{l}\text { : CARBON } \\
\text { Material } \\
\text { Obyek }\end{array}$ & STEEL \\
\hline D a t e & MAY, O4, 2006 & - & : SUPERHEATER TUBE 2" \\
\hline Mesin & & Standar Uji & \\
\hline Machine & ARL -SPARKSPECTROMETER & Standard & : ASTM A - 751 \\
\hline
\end{tabular}

\begin{tabular}{|c|c|c|c|c|c|c|}
\hline \multirow[b]{2}{*}{ NO. } & \multirow[b]{2}{*}{ Elements } & \multicolumn{2}{|c|}{ Hasil Pengujian (\% berat) } & \multicolumn{2}{|c|}{ Standar ASTM } & \multirow{2}{*}{ Ket. } \\
\hline & & Posisi 1 & Posisi 2 & SA-192 & SA-106 grade C & \\
\hline 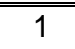 & $\overline{\mathrm{Fe}}$ & 988.46 & 99.23 & & & \\
\hline 2 & C & 0.15 & 0.13 & $0.06-0.18$ & 0.35 & Msk/tm \\
\hline 3 & $\mathrm{Si}$ & 0.20 & 0.23 & 0,25 & $0.1 \mathrm{~min}$ & $\mathrm{Rdh} / \mathrm{msk}$ \\
\hline 4 & $\mathrm{Mn}$ & 0.73 & 0.47 & $0.27-0.63$ & $0.29-1.06$ & Tng/msk \\
\hline 5 & $\mathrm{Cr}$ & 0.14 & 0.0 & & & \\
\hline 6 & $\mathrm{Ni}$ & 0.041 & 0.0 & & & \\
\hline 7 & Mo & 0.0 & 0.0 & & & \\
\hline 8 & $\mathrm{Cu}$ & 0.20 & 0.011 & & & \\
\hline 9 & $\mathrm{Ti}$ & 0.029 & -- & & & \\
\hline 10 & Al & 0.0039 & -- & & & \\
\hline 11 & $\mathrm{~V}$ & 0.015 & 0.014 & & & \\
\hline 12 & W & 0.034 & 0.033 & & & \\
\hline 13 & Co & -- & -- & & & \\
\hline 14 & $\mathrm{~s}$ & 0.011 & 0.016 & 0.058 & 0.058 & rendah \\
\hline 15 & $\mathrm{P}$ & 0.015 & 0.028 & 0.048 & 0.048 & rendah \\
\hline
\end{tabular}

\section{LAMPIRAN 2}

\begin{tabular}{|c|c|}
\hline Pemakai Jasa & Bahan \\
\hline $\begin{array}{l}\text { Customer } \\
\text { No. Kontrak }\end{array}$ & \\
\hline $\begin{array}{l}\text { Contract Nr. } \\
\text { No. Laporan }\end{array}$ & \\
\hline $\begin{array}{l}\text { Report No. } \\
\text { Tanggal }\end{array}$ & \\
\hline $\begin{array}{l}\text { D a t e } \\
\text { Sketsa }\end{array}$ & \\
\hline
\end{tabular}

$\begin{array}{ll}\text { Material } & \text { Carbon Steel } \\ \text { Object } & \\ ------- \text { : Sec.SuperheaterTube 2" } \\ \text { Obyek } & \\ \text { Standar Uji } & \\ \vdots & \text { DIN 50133 } \\ \text { Standard } & \\ \text { Mesin } & \\ --------- & \text { : Frank Finotest } \\ \text { Machine } & \end{array}$




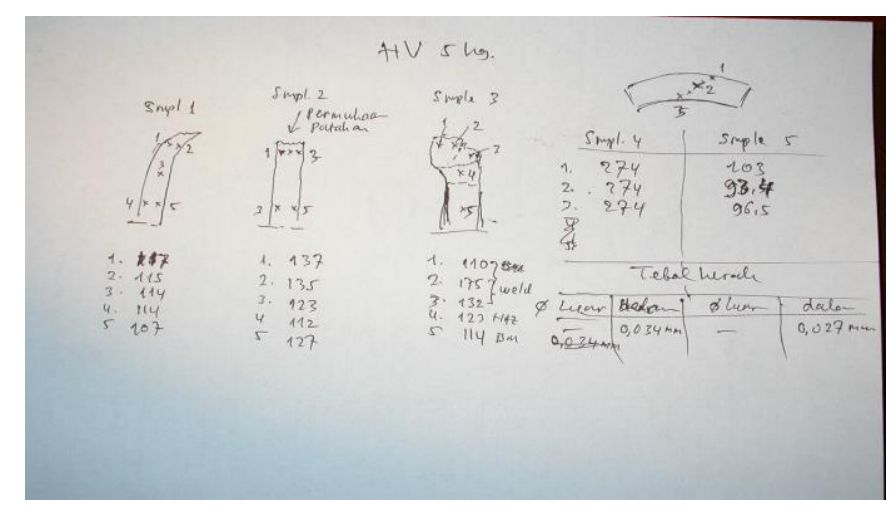

$\mathrm{x}=$ Test Location / Lokasi Uji

Permukaan

Surface
Metode Uji

Test Methode
Beban

: $5 \mathrm{~kg}$

Load

Waktu

--o- : 15 second

Time

\begin{tabular}{|c|c|c|c|c|c|}
\hline No. & Specimen Code & \multicolumn{2}{|c|}{ Hardness HV $\left(\mathrm{Kg} / \mathrm{mm}^{2}\right)$} & \multicolumn{2}{|c|}{ Average $\mathrm{HV} \quad\left(\mathrm{Kg} / \mathrm{mm}^{2}\right)$} \\
\hline & Sample 1 & & & & \\
\hline 1 & & 117 & & & \\
\hline 2 & & 115 & & & \\
\hline 3 & & 114 & & 113.4 & \\
\hline 4 & & 114 & & & \\
\hline 5 & & 107 & & & \\
\hline & Sample 2 & & & & \\
\hline 1 & & 137 & & & \\
\hline 2 & & 135 & & & \\
\hline 3 & & 123 & & 106.8 & \\
\hline 4 & & 112 & & & \\
\hline 5 & & 127 & & & \\
\hline & Sample 3 & & & & \\
\hline 1 & & 110 & WM & & \\
\hline 2 & & 175 & WM & 139 & \\
\hline 3 & & 132 & WM & & \\
\hline 4 & & 123 & HAZ & & \\
\hline 5 & & 114 & BM & & \\
\hline & Sample 4 & & & & \\
\hline 1 & & 274 & & & \\
\hline 2 & & 274 & & 274 & \\
\hline 3 & & 274 & & & \\
\hline & Sample 5 & & & & \\
\hline 1 & & 103 & & & \\
\hline 2 & & 93.4 & & 97.6 & \\
\hline 3 & & 96.5 & & & \\
\hline
\end{tabular}

